\title{
Adaptações estruturais de sete espécies ciófitas arbustivas de Floresta Ombrófila Densa
}

\author{
João Carlos Ferreira de Melo Júnior ${ }^{1,2}$, Maiara Matilde da Silva ${ }^{1}$, Maick Willian Amorim ${ }^{1}$ e \\ Emanoelle Garcia Ramos Tussolini ${ }^{1}$
}

Recebido: 6.09.2016; aceito: 1.03.2017

\begin{abstract}
Structural adaptations of seven shade shrubs in species of Tropical Rain Forest). Understory species are adapted to shade condition imposed by the canopy. This study characterized, by means of leaf attributes, the strategies used by different species of understory. The study was conducted at the Botanical Garden of the University of the Region of Joinville, Santa Catarina State, Brazil. Seven shade species were selected. Of each species, five individuals were selected and 25 leaves were collected for morphological and anatomical analysis and chlorophyll content. The incident light intensity on each specimen was measured. The results confirmed the high degree of shading in understory plants. The ratio chlorophyll a/b was $>1$ and therefore contrary to expected. Statistical tests showed the existence of patterns of response to shading, morphologically characterized by fresh weight, leaf area, length and width of the blade and leaf specific area and, anatomically, the thickness of the spongy parenchyma. The convergence of these attributes is associated with greater use of light that reaches the understory.
\end{abstract}

Keywords: leaf traits, light, rain forest, understory

RESUMO - (Adaptações estruturais de sete espécies ciófitas arbustivas de Floresta Ombrófila Densa). As espécies do subosque são adaptadas à condição de sombreamento imposta pelo dossel. O presente estudo caracterizou, por meio de atributos foliares, as estratégias utilizadas por diferentes espécies de subosque. O estudo foi realizado no Jardim Botânico da Universidade da Região de Joinville, SC, Brasil. Foram selecionadas sete espécies ciófitas. De cada espécie foram selecionados cinco indivíduos, dos quais 25 folhas foram coletadas para análise morfoanatômica e de teor de clorofila. A intensidade luminosa incidente sobre cada espécime foi medida. Os resultados confirmaram o alto grau de sombreamento das plantas em subosque. A razão clorofila a/b foi $>1$ e, portanto, contrária a esperada. Os testes estatísticos evidenciaram a existência de padrões de resposta ao sombreamento, caracterizados morfologicamente pela massa fresca, área foliar, comprimento e largura do limbo e área específica foliar e, anatomicamente, pela espessura do parênquima lacunoso. A convergência destes atributos está relacionada ao maior aproveitamento da luz que atinge o subosques.

Palavras-chave: atributos foliares, floresta atlântica, luminosidade, subosque

\section{Introdução}

A luz é um recurso primordial para o desenvolvimento vegetal, uma vez que é o principal componente para a fotossíntese (Folta \& Maruhnich 2007, Saraiva et al. 2014). Reguladora do crescimento vegetal, a luz pode variar no tempo e no espaço e, assim, implicar em ajustes estruturais nas plantas (Pugnaire \& Valladares 2007). Em florestas tropicais, apenas 2\% da radiação luminosa incidente sobre o dossel atinge o solo florestal (Chazdon 1988). Ao longo da estrutura vertical da Floresta Ombrófila Densa é notória a variação espacial da intensidade luminosa em função da organização vertical das espécies vegetais que, de maneira geral, estão distribuídas em três estratos (Gressler 2010). Espécies de plantas que crescem à sombra são estruturalmente diferentes daquelas que crescem em pleno sol (Valladares et al. 2004).

O conhecimento sobre os requerimentos de luz pelas espécies arbóreas tropicais é importante para melhor entender os processos naturais de sucessão ecológica, de recomposição de florestas e para otimizar o desenvolvimento de plantações de espécies economicamente importantes (Nakazono et al.

1. Universidade da Região de Joinville, Departamento de Ciências Biológicas, Laboratório de Anatomia e Ecologia Vegetal, Rua Paulo Maschitzki, 10, CEP 89219-710, Joinville, SC, Brasil

2. Autor para correspondência: jcmelo_wood@hotmail.com 
2001). Do ponto de vista ecológico, a compreensão de como a luz pode influenciar na composição e no desenvolvimento de uma comunidade vegetal torna-se um requisito fundamental para a conservação das florestas (Nakazono et al. 2001). Sabe-se que a ordenação das espécies vegetais segue diferentes níveis de tolerância à maior ou menor incidência luminosa, mas ainda se apoia em observações carentes de dados quantitativos (Valladares et al. 2004).

As espécies adaptadas à sombra (ciófitas) e ao sol (heliófitas) apresentam diferentes características foliares afim de maximizar seu fitness (Rizzini 1976). As ciófitas tipicamente apresentam menor teor de matéria seca devido ao maior investimento em tecido fotossintético, menor razão parênquima paliçádico/ lacunoso, menor razão de clorofilas a/b e menores taxas de fotossíntese, transpiração e crescimento relativo se comparadas às heliófitas (Lüttge 1997, Armelin \& Mantovani 2001, Larcher 2006).

Além disso, as ciófitas tendem a ter maior área específica foliar (AEF), proporcionando uma maior área de captação da luz para maximizar os processos fisiológicos (Campos \& Uchida 2002, Poorter \& Rozendaal 2008). A AEF é diretamente influenciada pela massa seca, área foliar, espessura do mesofilo, teor de água e tecidos de sustentação (Boeger et al. 2006) e em diferentes espécies tropicais têm sido demonstrado que as plantas em menores níveis de luz investem mais em produção de lâminas foliares maiores (Poorter \& Rozendaal 2008, Sabbi et al. 2010, Melo Jr. \& Boeger 2016). Ao nível fisiológico, o aumento da AEF implica em alterações da troca de carbono entre as folhas e a atmosfera (Nautiyal et al. 2002, Lichtenthaler et al. 2007), além de ajustes na densidade de estômatos para reduzir a perda de água (Aranda et al. 2004). Ao nível celular, a aclimatação à sombra envolve aumento na concentração de clorofilas totais por unidade de massa e redução na razão clorofila a/b (Boeger et al. 2009, Silva 2010), ao passo que a clorofila $\mathrm{b}$ atua como pigmento acessório (Taiz \& Zeiger 2004) convertendo-se em clorofila a e auxiliando na absorção de luz (Xu et al. 2001).

Sendo assim, a intensidade luminosa é tida como um dos fatores mais crítico de sobrevivência das espécies florestais uma vez que afeta suas estratégias de crescimento e sucessão ecológica (Poorter 2001). Apesar desta constatação ser mais amplamente reportada às plantas pioneiras (heliófitas) (Poorter et al. 2010), existem registros tão contundentes quanto que espécies não pioneiras têm potencial plástico para se ajustar à variação da luminosidade em função de características interespecíficas (Oguchi et al. 2005).
A baixa intensidade luminosa presente nos subosques pode agir como um filtro ambiental ao favorecer o desenvolvimento de espécies tolerantes à sombra e com capacidade de aclimatação aos diferentes níveis de sombreamento deste ambiente. O presente estudo teve como objetivo caracterizar e comparar sete espécies ciófitas arbustivas de um remanescente de Floresta Ombrófila Densa, por meio de atributos morfoanatômicos e ecofisiológicos foliares. A hipótese deste estudo apoia-se no pressuposto de que a baixa radiação luminosa que chega ao subosque florestal influencia a convergência de atributos funcionais entre as diferentes espécies de plantas.

\section{Material e métodos}

Local de Estudo - O estudo foi realizado no remanescente florestal pertencente ao Jardim Botânico da Universidade da Região de Joinville - Univille, região nordeste do Estado de Santa Catarina, Brasil. Possui área total de $19.160 \mathrm{~m}^{2}$ e está situado nas coordenadas geográficas: $26^{\circ} 15^{\prime} 12^{\prime \prime} \mathrm{S}$ e $48^{\circ} 51^{\prime} 26^{\prime \prime} \mathrm{W}$. A floresta é classificada como Floresta Ombrófila Densa de Terras Baixas (IBGE 2012) e está situada em relevo ondulado, com altitude de 21 metros. O clima da região é $\mathrm{Cfa}$, clima subtropical com verão quente e sem estação seca definida, segundo a classificação de Köppen. Apresenta temperatura média anual de $21.1{ }^{\circ} \mathrm{C}$, sendo janeiro o mês mais quente, com temperatura média de $25.1^{\circ} \mathrm{C}$ e julho o mês mais frio, com temperatura média de $17.1^{\circ} \mathrm{C}$. A precipitação média anual é de 1.706 mm (CLIMATE-DATE 2016).

Intensidade luminosa - Foram realizadas 10 medidas de intensidade luminosa, com o auxílio de luxímetro EMD THAL 300, na porção interna da copa de cada indivíduo amostral, registrando-se a radiação fotossinteticamente ativa (PAR, $\mu$ mol. $\mathrm{m}^{2} \cdot \mathrm{s}^{-1}$ ). As medidas de intensidade luminosa foram realizadas no mesmo dia e estação do ano, em horário de pico de máxima luminosidade (12:00h) em dia livre de instabilidades, como chuva e céu encoberto por nuvens.

Seleção de espécies - Foram selecionadas sete espécies ciófitas características do subosque da formação de Floresta Ombrófila Densa. São elas: Guapira opposita (Vell.) Reitz (Nyctaginaceae), Leandra carassana (DC.) Cogn. (Melastomataceae), Piper cernuum Vell. e Piper aduncum L. (Piperaceae), Psychotria carthagenensis Jacq., Psychotria nuda (Cham. \& Schltdl.) Wawra e Psychotria officinalis (Aubl.) Raeusch. ex Sandwith (Rubiaceae). 
Coleta de material e atributos estudados - Foram selecionados cinco indivíduos de cada espécie ciófita, nos quais foram coletadas dez folhas sadias totalmente expandidas. As folhas foram coletadas entre o $3^{\circ}$ e $6^{\circ}$ nós, no sentido ápice-base, de forma a se obter folhas completamente expandidas em ramos localizados na porção inferior da copa, sendo esta caracterizada pelo maior grau de sombreamento em função da sobreposição feita pelos ramos externos. Totalizou-se um $\mathrm{N}$ amostral de 50 folhas por espécie, sendo estas destinadas à morfologia. As folhas foram prensadas e secas em estufa de circulação forçada de ar a $70^{\circ} \mathrm{C}$.

Os atributos morfológicos avaliados foram: massa fresca e massa seca foliar (MFF e MSF, g), obtidas em balança analítica de precisão; área foliar (AF, $\mathrm{cm}^{2}$ ), mensurada por meio de imagem digitalizada em scanner de mesa acoplado ao software Sigma Scan Pro (versão 5.0, SPSS Inc., Chicago IL, USA); e a área específica foliar (AEF, $\left.\mathrm{cm}^{2} . \mathrm{g}-{ }^{1}\right)$, obtida por meio da razão entre a área foliar a massa seca foliar (Witkowski \& Lamont 1991); comprimento e largura do limbo (CL e LL, cm), medidos com auxílio de paquímetro digital Mitotoyo. O tamanho da lâmina foliar foi baseado na classificação proposta por Webb (1955), a qual denomina folha leptófila aquela com área $\leq 0,25 \mathrm{~mm}^{2}$; nanófila entre $0,25-2,25 \mathrm{~mm}^{2}$; micrófila entre 2,25-20,25 $\mathrm{mm}^{2}$; notófila entre: $20,25-45,0 \mathrm{~mm}^{2}$; mesófila entre 45,0-182, $25 \mathrm{~mm}^{2}$; macrófila entre $182,25-1640,25 \mathrm{~mm}^{2}$; e megáfila $\geq 1640,25 \mathrm{~mm}^{2}$ (LWG 1999).

Em adição, mais cinco folhas por espécie foram coletadas para a mensuração do teor de clorofila e análise anatômica. Optou-se por um menor número de folhas por indivíduo para evitar o efeito da pseudorreplicação por variações intraespecíficas. Utilizando folhas frescas, a porção do terço médio do limbo foi recortado e fixado em FAA (Formol, ácido acético e álcool 70\%) e, posteriormente, os cortes foram preservados em álcool $70 \%$. Secções transversais foram feitas à mão livre utilizando lâmina de aço do tipo gilete. Os cortes produzidos foram clarificados em hipoclorito de sódio $10 \%$, corados com azul de toluidina e montados em água glicerinada 30\% (O’brien \& Mccully 1981). O restante do material vegetal fresco foi utilizado na análise do teor de clorofila.

A análise anatômica considerou os atributos de espessura da epiderme das faces adaxial e abaxial, incluindo a cutícula (EAD e EAB, $\mu \mathrm{m})$, espessura do parênquima paliçádico (EPP, $\mu \mathrm{m})$, espessura do parênquima lacunoso (EPL, $\mu \mathrm{m})$ e espessura total do limbo (ETL, $\mu \mathrm{m})$. A ETL foi feita no terço médio da lâmina foliar em uma área sem nervuras. Foi calculada a razão entre EPP e EPL. As medidas anatômicas e as fotomicrografias foram obtidas por meio do uso do software Dino Eye 2.0 acoplado a microscópio de luz transmitida Olympus CX 200.

O conteúdo de clorofila foi considerado o atributo ecofisiológico do estudo. Sua obtenção se deu a partir da maceração a seco de $0,5 \mathrm{~g}$ de folha de cada indivíduo adicionado a $5 \mathrm{ml}$ de acetona $80 \%$ (Linder 1974). O conteúdo obtido foi transferido para tubos de ensaio revestidos com papel alumínio para evitar a fotooxidação da clorofila. As amostras foram centrifugadas por 10 minutos a 2000 RPM em centrífuga Sigma 3K12 (Linder 1974). Após a centrifugação, $0,5 \mathrm{ml}$ do extrato foi diluído em $5 \mathrm{ml}$ de acetona $80 \%$, transferindo-se posteriormente o sobrenadante para cubetas. As leituras foram realizadas em Espectrofotômetro Biospectro SP 22 com comprimentos de onda de 645 e $663 \mathrm{~nm}$, para estimar, respectivamente, os conteúdos de clorofilas a e b (Linder 1974). O conteúdo de clorofila total $(\mathrm{a}+\mathrm{b})$ foi calculado pela seguinte equação: clorofila $\mathrm{a}+\mathrm{b}=(20,2 \times \mathrm{A} 645+8,02 \times \mathrm{A} 663)$, onde: $\mathrm{A}=$ absorbância. Foi calculada a razão entre os teores de clorofilas a e b.

Análise estatística - Para todos os atributos foliares foram calculadas médias e desvio-padrão. Seguido o teste de normalidade dos dados, as médias destes atributos foram comparadas entre as espécies por meio de Análise de Variância (ANOVA), post hoc Tukey, com nível de significância de 5\%. A análise dos componentes principais (PCA) foi utilizada para determinar a maior variância entre os atributos selecionados. A relação entre os atributos foliares e a radiação luminosa incidente foi verificada por meio do teste de Correlação de Pearson. Todas as análises estatísticas foram realizadas em software R Studio com interface ao pacote R commander (Borcard et al. 2011).

\section{Resultados}

A intensidade luminosa incidente sobre $P$. aduncun e $P$. officinalis foi inferior $\left(<190 \mu \mathrm{mol} . \mathrm{m}^{2} . \mathrm{s}^{-1}\right)$, sobre G. opposita, P. cernuum e $P$. nuda a PAR foi intermédiária $\left(>300\right.$ e $\left.<400 \mu \mathrm{mol} . \mathrm{m}^{2} . \mathrm{s}^{-1}\right)$ e em P. carthagenensis e L. carassana os níveis de luz foram superiores $\left(>550 \mu \mathrm{mol} . \mathrm{m}^{2} . \mathrm{s}^{-1}\right)$ (tabela 1$)$.

A análise de variância (ANOVA) indicou similaridades e dissimilaridades entre as espécies para 
Tabela 1. Médias e respectivos desvios-padrão da radiação fotossinteticamente ativa (PAR) incidente sobre as espécies ciófitas estudadas. As letras representam diferenças estatisticamente significantes pelo teste de Tukey $(\mathrm{p}=0,05)$.

Table 1. Means and standard deviations of photosynthetically active radiation (PAR) on shade species. The letters represent statistically significant differences with Tukey test $(\mathrm{p}=0.05)$.

\begin{tabular}{llcccccc}
\hline \multirow{2}{*}{ Espécie } & Guapira & Leandra & Piper & Piper & Piper & Psychotria & Psychotria \\
& opposita & carassana & cernumm & aduncun & officinalis & nuda & carthagenensis
\end{tabular}

PAR

PAR
$\left(\mu \mathrm{mol} \cdot \mathrm{m}^{2} \cdot \mathrm{s}^{-1}\right)$

$388 \pm 2,71^{\mathrm{ab}} \quad 570 \pm 1,78^{\mathrm{a}} \quad 349 \pm 2,02^{\mathrm{ab}} \quad 179 \pm 0,98^{\mathrm{b}} \quad 181 \pm 0,97^{\mathrm{b}} \quad 310 \pm 2,86^{\mathrm{ab}} \quad 596 \pm 1,84^{\mathrm{a}}$

as características morfoanatômicas, enquanto que os teores de clorofila a e b mostram-se mais uniformes entre as espécies. Os maiores teores de clorofilas a e b foram registrados nas espécies $G$. opposita e $P$. cernuum e os menores teores foram registrados em Piper officinalis e Psychotria nuda (tabela 2).

Folhas com maiores valores de massa fresca, massa seca e área foliar foram registradas em Piper cernuum, sendo classificada como notófila. As demais espécies possuem folhas classificadas como micrófilas, mas com pequenas variações de área, sendo Piper aduncum e Leandra carassana portadoras de folhas $>100 \mathrm{~cm}^{2}$ e as demais espécies com área $<100 \mathrm{~cm}^{2}$.

A AEF manteve-se similar entre as espécies ciófitas, exceto em $G$. opposita e $P$. aduncun que tiveram os menores valores para este atributo. O comprimento e a largura foliar aproximaram as espécies de forma tênue, mas exibiram maior convergência entre $P$. cernuum, $P$. aduncun e L. carassana.

A espessura da face adaxial da epiderme mostrou-se mais elevada que a da face abaxial em todas as espécies estudadas. O mesofilo de todas as espécies apresentou organização dorsiventral. O parênquima lacunoso mostrou-se mais desenvolvido que o parênquima paliçádico para as folhas de todas as espécies. A razão parênquima lacunoso/paliçádico apresentou para todas as espécies valores $>1,08 \mathrm{e}$ $<3,63$ (tabela 2), sendo os maiores valores encontrados para as espécies Guapira opposita, Psychotria nuda e Psychotria carthagenensis, respectivamente.

A correlação de Pearson mostrou interações fracas e negativas entre a luz e atributos foliares estudados. A $\mathrm{AEF}$, a massa seca e a área foliar apresentaram fraca correlação negativa com a intensidade luminosa ( $\mathrm{r}$ $=-0,15, \mathrm{df}=163, \mathrm{p}=0,02 ; \mathrm{r}=-0,30, \mathrm{p}<0,0001$ e $\mathrm{r}$ $=-0,28, p=0,0002$, respectivamente). A análise de componentes principais (PCA) mostrou que os dois primeiros eixos explicaram juntos $73,90 \%$ da variância total dos dados (tabela 3, figura 1). A massa fresca e a área foliar foram mais relacionadas ao eixo principal 1, que explicou $48,10 \%$ da variância. Já o eixo principal 2 explicou $25,80 \%$ da variância e esteve mais relacionado aos atributos de comprimento e largura do limbo e área específica foliar. No componente principal 1 observa-se um agrupamento das espécies Guapira opposita, Psychotria nuda e Psychotria carthagenensis. No componente principal 2 nota-se maior agrupamento entre as espécies Leandra carassana, Piper aduncum e Piper officinalis. Em ambos os componentes Piper cernuum mostra-se uma espécie isolada.

O aparente isolamento de $P$. cernuum, em relação às demais espécies ciófitas exibido pela PCA, é atribuído aos atributos morfoanatômicos, com destaque à área foliar, cujos elevados valores médios representam as características peculiares desta espécie. Por outro lado, ao serem observados os atributos que mostram proporcionalidades (AEF, razão entre parênquima paliçádico e lacunoso e razão clorofilas a/b) todas as espécies estudadas tornam-se similares e evidenciam a convergência de atributos funcionais ao sombreamento.

\section{Discussão}

Plantas que se desenvolvem em locais com disponibilidade de luz restrita frequentemente apresentam adaptações morfoanatômicas e ecofisiológicas afim de otimizar a interceptação da luz difusa que incide no subosque (Givnish 1988). A luz, portanto, atua como um agente seletivo, gerando uma convergência de atributos foliares (Givnish 1988, Valladares et al. 2004). De forma geral, dentre as caraterísticas morfoanatômicas avaliadas, os atributos morfológicos apresentaram maior variação entre as espécies quando comparados aos atributos anatômicos 


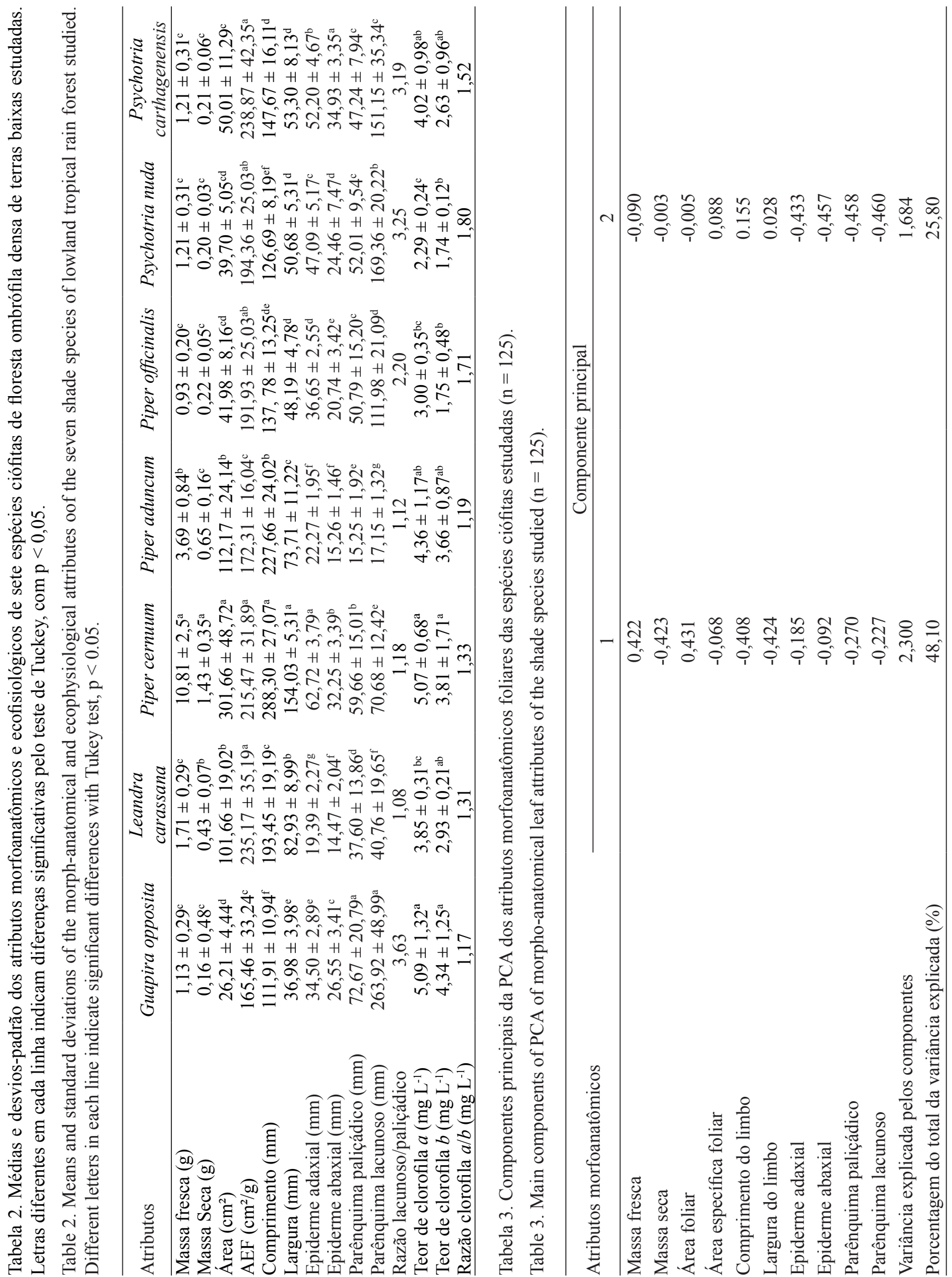




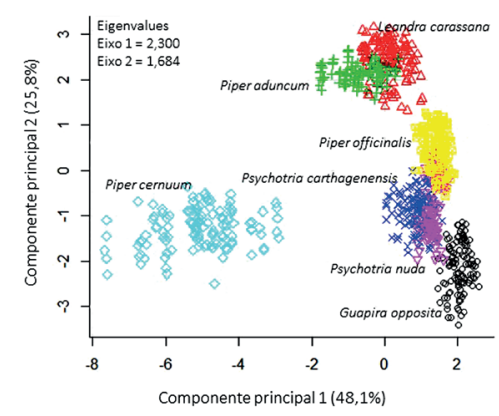

Figura 1. Análise de componentes principais dos atributos morfoanatômicos foliares das espécies ciófitas estudadas. Os dois primeiros eixos principais explicam $48,1 \%$ e $25,8 \%$ da variância dos dados, respectivamente.

Figure 1. Principal component analysis of the correlation matrix of leaf morphological and anatomical attributes of ciófitas species. The first two main axes explained $48.1 \%$ and $25.8 \%$ of the variance of the data, respectively.

que, por sua vez, mostraram o padrão esperado para plantas que se desenvolvem em baixas condições de luminosidade.

Dentre os atributos morfológicos quantitativos avaliados, a massa fresca e a área foliar explicaram a maior convergência estrutural entre as espécies, e tais atributos funcionais podem otimizar a alocação dos recursos disponíveis (Givnish 1984). Este padrão associado ao sombreamento é suportado em função de serem observadas, em condições de exposição à maiores níveis de luminosidade, folhas com baixos valores de massa fresca e área foliar reduzida ( $\mathrm{Li}$ et al. 2014, Nery et al. 2016). Os altos valores de massa fresca quando comparados aos de massa seca foliar, associados a maior espessura da epiderme nas faces adaxial e abaxial, sugerem que as espécies estudadas tendem a armazenar água nas células epidérmicas (Boeger et al. 2006). Além do alto valor de massa fresca, a AEF destas espécies indica mesofilia (AEF > 0.6) (Rizzini 1976). Ou seja, folhas com altos valores de AEF apresentam maior investimento em tecido fotossintético em detrimento do tecido mecânico, apresentando assim maior quantidade de tecidos para armazenamento de água (Vendramini et al. 2002) se comparadas às folhas esclerófilas.

A mesofilia nas espécies deste estudo, representada por altos valores de AEF, corrobora os resultados obtidos para seis espécies ciófitas de Floresta Ombrófila Mista (Boeger et al. 2006). Entre as características morfológicas foliares estudadas, a AEF é tida como um dos principais indicadores da taxa de crescimento e de estratégias do uso de recursos pelas plantas (Vendramini et al. 2002), sendo que o seu incremento pode traduzir-se como um mecanismo que permite aumentar a interceptação total da luz pelas plantas que se desenvolvem em ambientais mais sombreados (Niinemets \& Fleck 2002). Este padrão de resposta funcional tem sido observado em diferentes espécies submetidas ao sombreamento, como em Schinus terenbitifolius Raddi (Anacardiaceae) submetido à sombra em área de capoeira, com valor de AEF superior a $80 \mathrm{~cm}^{2} \cdot \mathrm{g}^{-1}$ (Sabbi et al. 2009); em Ilex aquifolium L. (Aquifoliaceae) (Valladares et al. 2005); e em Mikania glomerata Spreng (Asteraceae) (Espíndola Jr. et al. 2009). Em trabalho com espécies medicinais, Boeger et al. (2009) demonstraram que a AEF está negativamente relacionada com a intensidade luminosa e, assim, há um maior investimento em tecido fotossintético para maximizar o aproveitamento da luz difusa recebida em ambientes sombreados.

A organização dorsiventral do mesofilo e a assimetria na composição dos parênquimas clorofilianos em números de camadas celulares é reportada como característica típica das dicotiledôneas (Fahn 1990). No entanto, a intensidade luminosa incidente na superfície da folha pode interferir no desenvolvimento dos parênquimas de assimilação (Kozuda et al. 2011). O desenvolvimento dos parênquimas paliçádico e lacunoso varia de acordo com a intensidade luminosa que atinge as folhas (Givnish 1988). Em ambientes com maior luminosidade o parênquima paliçádico é mais desenvolvido, pois o formato colunar das células possibilita o maior aproveitamento dos feixes de luz incidentes diretamente sobre a folha e a sua distribuição uniforme para os cloroplastos (Taiz \& Zeiger 2004).

Em folhas adaptadas à sombra, o maior desenvolvimento do parênquima lacunoso maximiza o aproveitamento da luz difusa devido ao formato irregular das células e dos espaços intercelulares que aumentam a reflexão e refração da luz dentro do mesofilo (Paiva et al. 2003). Por outro lado, em plantas de sol o parênquima paliçádico tende a ser mais desenvolvido para absorver luz direta, conforme observado em diversos ambientes (Givnish 1988, Espíndola Jr. et al. 2009, Melo Jr. \& Boeger 2015). As espécies deste estudo apresentaram o parênquima lacunoso mais espesso do que o parênquima paliçádico, provavelmente, devido à baixa incidência luminosa neste local, corroborando o padrão observado em outros estudos (Fermino et al. 2004, Boeger et al. 2006, Boeger et al. 2009, Espíndola Jr. et al. 2009). 
Em Psychotria carthagenensis sob diferentes condições de luz, Vitarelli (2008) observou o maior desenvolvimento de parênquima lacunoso em plantas de subosque, assim como o observado em Guapira opposita por Fermino (2004). O desenvolvimento diferenciado do parênquima lacunoso foi evidenciado pela razão parênquima lacunoso/paliçádico $>1$, evidenciando o padrão esperado de resposta anatômica foliar à diferentes graus de sombreamento (Espíndola Jr et al. 2009, Melo Jr. \& Boeger 2016).

Do ponto de vista ecofisiológico, folhas de sombra apresentam maior concentração de clorofila em relação às folhas de sol (Boardman 1977). Nas folhas de sol ocorre maior síntese de clorofila a, enquanto a clorofila $\mathrm{b}$ atua como pigmento acessório (Taiz \& Zeiger, 2004), podendo converter-se em clorofila a e auxiliar na absorção de luz (Xu et al. 2001). Assim, em diferentes espécies, a razão clorofila $\mathrm{a} / \mathrm{b}$ é reduzida quando associados à baixa incidência luminosa, como o registrado em Passiflora alata Curtis (Passifloraceae) (Freitas et al. 2012), Pseudobombax grandiflorum (Cav.) A. Robyns (Malvaceae) (Portes et al. 2010), Joannesia princeps Vellozo (Euphorbiaceae) (Silva 2010) e Maytenus ilicifolia Mart. ex Reissek (Celastraceae) (Boeger et al. 2009). Da mesma forma como o observado neste estudo, vários trabalhos têm mostrado que a razão clorofila a/b para espécies heliófitas é maior que 3 , enquanto que em espécies ciófitas esta razão cai para valores pouco superiores a 1 (Almeida et al. 2005, Lichtenthaler 2007, Boeger et al. 2009, Dousseau 2009, Barros et al. 2012, Li et al. 2014, Nery et al. 2016), o que pode ser explicado por variações nos níveis de luz dentro do sobosque em função da movimentação das copas pelos ventos (Fermino 2004). Outro aspecto a ser considerado é a variação luminosa no subosque provocada pela proximidade das espécies ciófitas às clareiras na floresta, situação esta observada neste estudo.

A convergência de certos atributos funcionais, predita pela hipótese deste estudo, mostra a existência de um padrão de respostas adaptativas desenvolvidas pelas plantas de subosque para melhor otimização da baixa radiação luminosa que atinge o estrato sombreado do ambiente florestal. A convergência em alto valores de AEF indica alto investimento em tecido fotossintético como uma estratégia para maximizar o aproveitamento da luz. A maior similaridade anatômica entre as espécies ciófitas estudadas sugere a influência efetiva da condição lumínica sobre o desenvolvimento dos tecidos fotossintetizantes.

\section{Literatura citada}

Almeida, S.M.Z., Soares, A.M., Castro, E.M.V., Gajego, C.V. \& Bordignon, E. 2005.Alterações morfológicas e alocação de biomassa em plantas jovens de espécies florestais sob diferentes condições de sombreamento. Ciência Rural 35: 62-68.

Aranda, I., Pardo, F., Gil, L. \& Pardos, J.A. 2004. Anatomical basis of the change in leaf mass per area and nitrogen investiment with relative irradiance within the canopy of eight temperate tree species. Acta Oecologica 25: 187-195.

Armelin, R.S. \& Mantovani, W. 2001. Definição de clareira natural e suas implicações no estudo da dinâmica sucessional das florestas. Rodriguésia 52: 5-15.

Barros, F.V., Goulart, M.F., Telles, S.B., Lovato, M.B., Valladares, F., \& Lemos-Filho, J.P. 2012. Phenotypic plasticity to light of two congeneric trees from contrasting habitats: Brazilian Atlantic Forest versus cerrado (savanna). Plant Biology 14: 208-215.

Boardman, N.K. 1977. Comparative photosynthesis of sun and shade plants. Annual Review of Plant Physiology 28: 355-377.

Boeger, M.R.T., Kaehler, M., Melo Júnior, J.C.F., Gomes, M.Z., Chaves, C.R.M., \& Scholttz, E.S. 2006. Estrutura foliar de seis espécies de subosque de um remanescente de Floresta Ombrófila Mista. Hoehnea 33: 521-531.

Boeger, M.R.T., Júnior, A.E., Júnior, A.M., Reissmann, C.B., Alves, A.C.A. \& Rickli, F.L. 2009.Variação estrutural foliar de espécies medicinais em consórcio com erva-mate, sob diferentes intensidades luminosas. Revista Floresta 9: 215-225.

Borcard, D., Gillet, F. \& Legendre, P. 2011. Numerical Ecology with R. Springer, New York.

Campos, M.A.A. \& Uchida, T. 2002. Influência do sombreamento no crescimento de mudas de três espécies amazônicas. Pesquisa Agropecuária Brasileira 37: 281-288.

Chazdon, R.L. 1988. Sunflecks in the forest understory. Advances in Ecological Research 18: 1-63.

CLIMATE-DATA. 2016. Temperatura. Disponível em http://pt.climate-data.org/location/28141/ (acesso em 02-08-2016).

Dousseau, S. 2009. Propagação, características fotossintéticas, estruturais, fitoquímicas e crescimento inicial de Piper aduncum L. (Piperaceae). Dissertação de Mestrado, Universidade Federal de Lavras, Lavras.

Espindola Júnior, A., Boeger, M.R.T., Maccari Júnior, A., Reissmann, C.B. \& Rickli, F.L. 2009. Variação na estrutura foliar de Mikania glomerata Spreng. (Asteraceae) sob diferentes condições de luminosidade. Revista brasileira de Botânica 32: 749-758.

Fahn, A. 1990. Plant anatomy. 4 ed. Pergamon Press, New York. 
Fermino Junior, P.C.P. 2004. Anatomia ecológica comparada de folhas de Guapira opposita (Vell.) Reitz (Nyctaginaceae) na vegetação de restinga e na Floresta Ombrófila Densa. Dissertação de Mestrado, Universidade Federal de Santa Catarina, Santa Catarina.

Folta, K.M. \& Maruhnich, S.A. 2007.Green light: a signal to slow down or stop. Journal of Experimental Botany 58: 3099-3111.

Givnish, T.J. 1984. Leaf and canopy adaptations in tropical forests. In: E. Medina, H.A. Mooney \& C. VasquesYanes (eds.). Physiological ecology of plants in the wet tropics. Junk publishers, Hague, pp. 51-84.

Givnish, T.J. 1988. Adaptation to sun vs. shade: a whole-plant perspective. Australian Journal of Plant Physiology 15: 63-92.

Gressler, E. 2010. Fenologia de espécies de floresta atlântica, núcleo Picinguaba, Parque Estadual da Serra do Mar, Estado de São Paulo: comparação entre estratos e influência de borda natural. Tese de Doutorado, Universidade Estadual Paulista, Rio Claro.

IBGE. 2012. Manual Técnico da Vegetação Brasileira: sistema fitogeográfico, Inventário das formações florestais e campestres. Técnicas e manejo de coleções botânicas e Procedimentos para mapeamentos. Instituto Brasileiro de Geografia e Estatística, Rio de Janeiro.

Kozuka, T., Kong, Sam-Geun., Doi, M., Shimazaki, Ken-ichiro. \& Nagatani, A. 2011. Tissue-autonomous promotion of palisade cell development by phototropin 2 in Arabidopsis. Plant Cell 23: 3684-3695.

Larcher, W. 2006. Ecofisiologia vegetal. RiMa, São Carlos. Li, Q, Deng, M, Xiong, Y, Coombes, A \& Zhao, W. 2014. Morphological and Photosynthetic Response to High and Low Irradiance of Aeschynanthus longicaulis. Scientific World Journal 347461: 1-8.

Lichtenthaler, H.K., Ac, A., Marek, M.V., Kalina, J. \& Urban, O. 2007. Differences in pigment composition, photosynthetic rates and chlorophyll fluorescence images of sun and shade leaves of four tree species. Plant Physiology and Biochemistry 45: 577-588.

Linder, S.A. 1974. proposal for the use of standradized methods for chlorophyll determinations in ecological and ecophysiological investigations. Physiologia Plantarum 32: 154-156.

Lüttge, U. 2008. Physiological ecology of tropical plants. Springer-Verlag Berlin Heidelberg, Germany.

LWG. 1999. Manual of Leaf Architecture - morphological description and categorization of dicotyledonous and net-veined monocotyledonous angiosperms. Leaf ArchitectureWorking Group, Washington.

Melo Júnior, J.C.F. \& Boeger, M.R.T. 2016. Leaf traits and plastic potential of plant species in a light-edaphic gradient from restinga in southern Brazil. Acta Biologica Colombiana 21: 51-62.
Nakazono, E.M., Costa, M.C., Futatsugi, K. \& Paulilo, M.T.S. 2001. Crescimento inicial de Euterpe edulis Mart. em diferentes regimes de luz. Revista Brasileira de Botânica 24: 173-179.

Nautiyal, M.C., Prakash, V. \& Nautiyal, B.P. 2002. Cultivation techniques of some high altitude medicinal herbs. Annual Forestry 10: 62-67.

Nery, F.C., Prudente, D. O., Alvarenga, A.A. Paiva, R. \& Nery, M.C. 2016. Desenvolvimento de mudas de guanandi (Calophyllum brasiliensis Cambess.) sob diferentes condições de sombreamento. Revista Brasileira de Biociências 14:187-192.

Niinemets, U. \& Fleck, S. 2002. Petiole mechanics, leaf inclination, morphology, and investment in support in relation to light availability in the canopy of Liriodendron tulipifera. Oecologia 132: 21-33.

Oguchi, R., Hikosaka, K. \& Hirose, T. 2005. Leaf anatomy as a constraint for photosynthetic acclimation: differential responses in leaf anatomy to increasing growth irradiance among three deciduous trees. Plant Cell Environ 28: 916-927.

Poorter, L. 2001. Light-dependent changes in biomass allocation and their importance for growth for rain forest tree species. Functional Ecology 15:113-123.

Poorter, L. \& Rozendaal, D.M.A. 2008. Leaf size and leaf display of thirty-eight tropical tree species. Oecologia 158: 35-46.

Poorter, L., McDonald, I., Alarco, A., Fichtler, E., Licona, J.C., Penã-Claros, M., Sterck, F., Villegas, Z. \& Sass-Klaassen, U. 2010. The importance of wood traits and hydraulic conductance for the performance and life history strategies of 42 rainforest tree species. New Phytologist 185: 481-492.

Portes, M.T., Damineli, D.S.C., Robeiro, R, Monteiro, J.A.F. \& Souza, G.M. 2010. Evidence of higher photosynthetic plasticity in the early successional Guazuma ulmifolia Lam. compared to the late successional Hymenaea courbaril L. grown in contrasting light environments. Brazilian Journal Biology 70: 75-83.

Pugnaire, F.I. \& Valladares, F. 2007. Functional plant ecology. CRC Press, New York.

Rizzini, C.T. 1976. Tratado de fitogeografia do Brasil: aspectos ecológicos. Hucitec, Edusp, São Paulo.

Sabbi, L.B.C., Ângelo, A.C. \& Boeger, M.R.T. 2010. Influência da luminosidade nos aspectos morfoanatômicos e fisiológicos de folhas de Schinus terebinthifolius Raddi (Anacardiaceae) implantadas em duas áreas com diferentes graus de sucessão, nas margens do Reservatório Iraí, Paraná, Brasil. Iheringia 65: 171-181.

Saraiva, G.F.R., Souza, G.M. \& Rodrigues, J.R. 2014. Aclimatação e fisiologia de mudas de guanandi cultivadas em telas de sombreamento foto-protetoras. Colloquium Agrariae 10: 1-10. 
Silva, L.A. 2010. Plasticidade e aclimatação foliar à irradiância em espécies da floresta atlântica. Tese de Doutorado, Universidade Federal de Viçosa, Viçosa.

Taiz, L. \& Zeiger, E. 2004. Fisiologia Vegetal. 3 ed. Artmed, Porto Alegre.

Valladares, F., Vilagrosa, A., Peñuelas, J., Ogaya, R., Camarero, J.J., Corcuera, L., Siso, S. \& Gil-Pelegrin, E. 2004. Estrés hídrico: ecofisiología y escalas de la sequía. In: F. Valladares (ed.). Ecologia del bosque mediterráneo en un mundo cambiante. Ministerio de Medio Ambiente, EGRAF S.A., Madrid, pp. 163-190.

Valladares, F., Arrieta, S., Aranda, I., Lorenzo, D., Sanchez-Gomez, D., Tena, D., Suárez, F. \& Pardos, J.A. 2005. Shade tolerance, photoinhibition sensitivity and phenotypic plasticity of Ilex aquifolium in continental Mediterranean sites. Tree Physiology 25: 1041-1052.
Vendramini, F., Díaz, S., Gurvich, D.E., Wilson, P.J., Thompson, K. \& Hodgson, J.G. 2002. Leaf traits as indicators of resource-use strategy in floras with succulent species. New Phytologist 154: 147-157.

Vitarelli, N.C. 2008. Morfoanatomia foliar da reófita facultativa Psychotria carthagenensis Jacq. (Rubiaceae). Dissertação de Mestrado, Universidade Federal de Santa Catarina, Florianópolis.

Webb, L.J. 1955. A physiognomic classification of Australian rain forests. Journal of Ecology 47: 551-570.

Witkowski, E.T.F. \& Lamont, B.B. 1991. Leaf specific mass confounds leaf density and thickness. Oecologia, 88: 486-493.

Xu, H., Vavilin, D. \& Vermaas, W. 2001. Chlorophyll b can serve as the major pigment in functional photosystem II complexos of cyanobacteria. Proceedings of the National Academy of Sciences 98: 14168-14173. 